\title{
Research on the Controlling Effect of NPR Cables for Anti-Dip Slope Based on the Numerical Simulation
}

\author{
Xiaohu Zhang, ${ }^{1}$ Hongjian Wang $\mathbb{D}^{2}$ Zhigang Tao $\mathbb{D}^{3},{ }^{3}$ and Chun Zhu $\mathbb{D}^{2,3}$ \\ ${ }^{1}$ School of Civil Engineering, Guizhou University of Engineering Science, Bijie 551700, China \\ ${ }^{2}$ Henan Key Laboratory of Geological Environment Intelligent Monitoring and Disaster Prevention, \\ North China University of Water Resources and Electric Power, Zhengzhou 450046, China \\ ${ }^{3}$ State Key Laboratory for Geomechanics \& Deep Underground Engineering, China University of Mining and Technology, \\ Beijing 100083, China
}

Correspondence should be addressed to Hongjian Wang; whj_1986@sina.cn and Zhigang Tao; taozhigang@263.net

Received 28 September 2021; Revised 24 October 2021; Accepted 27 October 2021; Published 19 November 2021

Academic Editor: Xuepeng Zhang

Copyright $(2021$ Xiaohu Zhang et al. This is an open access article distributed under the Creative Commons Attribution License, which permits unrestricted use, distribution, and reproduction in any medium, provided the original work is properly cited.

As the scale and depth of mines increase, large deformations of high-steep slopes progressively become prominent. Compared with the ordinary cables, negative Poisson's ratio (NPR) cables can provide a constant resistance force and high deformation inhibition during slope deformation, avoiding the occurrence of slope instability hazards. Consequently, the control effects on the toppling failures of slopes were necessary to be researched. Changshanhao open-pit gold mine was taken as an example; based on the field geological investigation and rock mechanics testing, a three-dimensional engineering geological model of open-pit mine was constructed. Subsequently, the stability of open pit in current situation and final boundary situation was estimated with FLAC3D software, for the potential slope vulnerable areas to be comprehensively identified. Finally, the control effects of ordinary cables and NPR cables on the instable W13 slope section were compared and studied through FLAC3D simulations, and the reinforcement effects of NPR cable on the anti-dip slope were proved as significant; meanwhile, the corresponding reinforcement methods in the failure mine areas were proposed, laying a reference for the instability failure control and reinforcement of similar anti-dip slopes.

\section{Introduction}

Slope stability of open-pit mine constitutes a long-term research topic accompanied by open-pit mining. In China, high proportion of open-pit mining projects in mines exists, at which landslides in the open-pit mines could result in significant economic losses and large number of casualties. Therefore, slope instability has become the most important issue that affects and perplexes the safe operation of mines [1-3]. Through slope stability analysis, the change trend of slope stability could be grasped in time, while the potential damage could be found and the corresponding measures could be taken ahead of time, to avoid unnecessary losses. Many scholars have carried out research on slope stability evaluation and landslide prediction [4-7]. As an example, Zhang et al. built a new recognition model to assess the risk grade of expansive soil slope stability during construction, and the rationality of the proposed model was proved [8]. He et al. proposed an analytical method to obtain the limit solutions of slope stability under both dynamic and static conditions [9]. Wu et al. utilized the three-dimensional discrete element code (3DEC) software to build a model considering the local joint sets, while the accuracy of the simulated landslide impact area was assessed through a comparison with a local aerial photograph [10].

Based on the evaluation of slope stability, the reasonable measures were put forward to control the potential instability. Currently, many scholars have conducted significant studies to guide the slope reinforcement [11-13]. Su et al. proposed the stress-based local factor of safety to analyze slope stability, and the corresponding stress-based program was developed [14]. The southern part of Wuchangping 
mine was taken as example. In this case, Zou et al. used the methods of limit equilibrium analysis, neural network, and finite element simulation to evaluate the slope stability [15]. Root reinforcement was practically applied to the coastal slope protection, and Wang et al. deduced the general mathematical equation of the root resist-slipping stress [16]. Ye et al. built the ground motion analysis model of slope reinforced by a frame with prestressed bolts, and the dynamic response of the reinforced slope under earthquake was obtained [17]. Nian et al. conducted the calculations through a technique, and the seismic stability of a slope reinforced with piles was analyzed [18].

Currently, the control measures used for slope reinforcement, such as cables, bolts, and retaining walls, belong to small deformation materials or rigid materials, which cannot resist the special toppling failure deformation, resulting in sudden large deformation and landslides of slope in open-pit mine. In addition, rocks have creep and deterioration characteristics; as the deformation of slope as well as the force exerted by landslide body on cable increased, when the cable force exceeded the tensile strength of the cable itself, the cables presented breakage. Subsequently, collapses and landslides occur. Moreover, NPR cable could maintain constant resistance force and large deformation during slope instability. Consequently, it was necessary to research the control effects on the toppling failure of slope. Changshanhao open-pit mine was taken as an example. Through the slope stability analysis of overall mining area and selection of 13 slope sections in current and final boundary situations, the potential instability areas of mining area after the excavation of final boundary were identified. Finally, the control effects of PR and NPR cables on the instable W13 section slope were compared and studied through FLAC3D software, and the control effects of NPR cable on the toppling failure of slope were proved.

\section{Engineering Background}

2.1. Geographical Characteristics. Changshanhao mine is located in Inner Mongolia province, and the elevation of study area is between 1550 and $1750 \mathrm{~m}$ (Figure 1). The mining area had wide temperature differences and scarce rainfall. The annual maximum temperature was $35 \sim 37^{\circ} \mathrm{C}$, and rainfall period was mainly concentrated between July and September.

2.2. Regional Geological Structural Characteristics. The main lithological compositions in the area included mica quartz schist, quartzite, limestone, gneiss, andalusite schist, and metasandstone. The geological structure in this area was complex, and the faults were mainly ductile shear zones sliding on the left side and NW-oriented translation faults. Controlled by stratum joint structures, the rock integrity of slope was relatively weak [19]. Consequently, local landslides and toppling deformation were likely to occur during mining. Moreover, the mining area was characterized by drought, less rain, and strong evaporation.

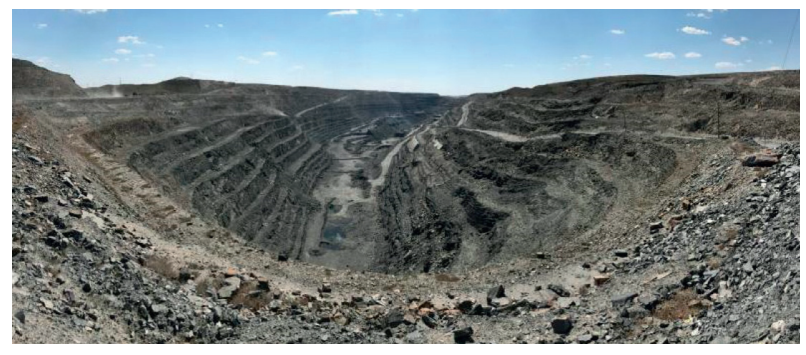

FIgURE 1: Overview of Changshanhao open-pit mine.

2.3. Current Situation and Problems in Mining Area. With the increase of height of slope, the frequency of landslides became more frequent, while landslides of different scales occurred in many areas (Figure 2), which severely threatened the safety of open-pit mining operation. From the distribution of landslides, the southwest pit was concentrated at the northern side. At present, these landslide areas could be slightly controlled through local square cutting, platform widening, and stage height and slope angle reduction to maintain mining production. Although certain areas were strengthened with ordinary cables, the ordinary cables easily broke under the large deformation of slope. Moreover, large-scale landslides still occurred in the reinforcing area, which severely threatened the mine production safety (Figure 2(b)).

2.4. Physical and Mechanical Properties of Rock. The representative rock samples in this open-pit mine are selected, and many rock physical and mechanical tests were conducted. These parameters could provide references for the structure feature analysis and quality evaluation of rock mass in the Changshanhao mine, and these test results are shown in Table 1.

\section{Three-Dimensional Engineering Geological Modeling and Slope Stability Evaluation}

3.1. Establishment of Engineering Geological Model. In order to clarify the influence of engineering geological conditions and design mining boundary on the slope stability of Changshanhao mine, an engineering geological model of southwest pit in Changshanhao mine was built, which provided the basis for the follow-up slope stability analysis.

In this calculation, the model parameters were firstly obtained referred to the laboratory rock mechanics test results, while through the inversion simulation of selected several typical landslides, the parameters obtained from laboratory tests were adjusted through engineering experience reduction method and landslide parameter inversion method. Furthermore, the rock mass strength parameters suitable for Changshanhao mine were determined (Table 2). Subsequently, the inversion parameters were used to calculate the stability of open-pit mine. Finally, the local section of the mining area was calculated, while the slope stability and final boundary situation were obtained. 


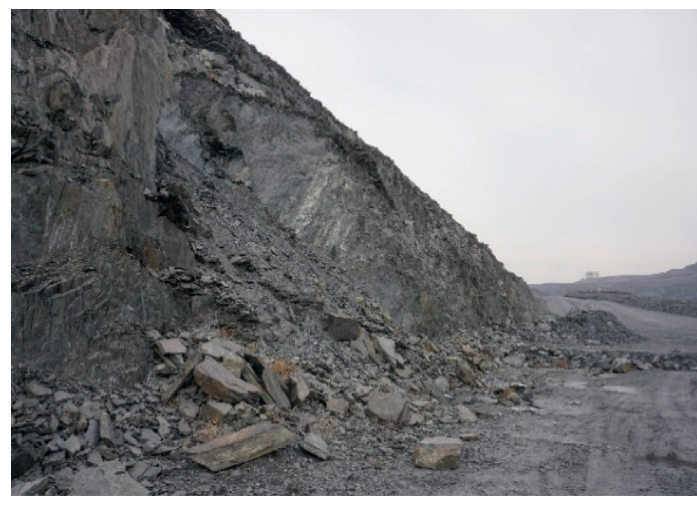

(a)

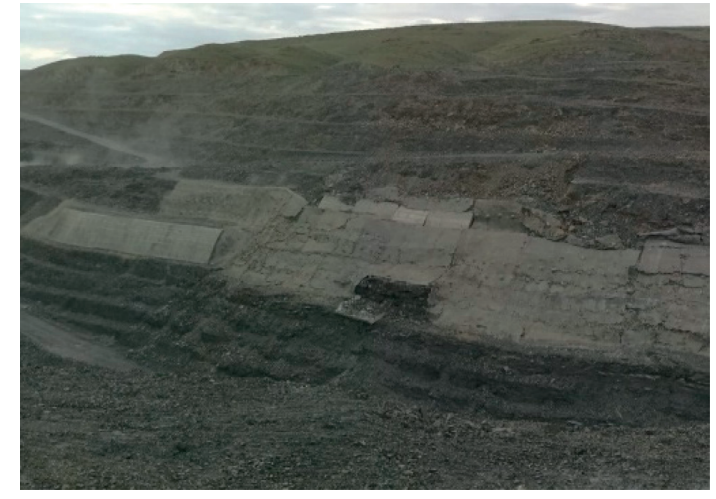

(b)

FIGURE 2: Instability failure of open-pit mine in current situation. (a) Collapse in mining area. (b) Re-instability of reinforced area.

TABLE 1: Physical and mechanical parameters of rocks [19].

\begin{tabular}{|c|c|c|c|c|c|c|c|}
\hline Lithology & $\begin{array}{l}\text { UCS } \\
(\mathrm{MPa})\end{array}$ & $\begin{array}{c}\text { Elastic modulus } \\
(\mathrm{GPa})\end{array}$ & $\begin{array}{l}\text { Poisson's } \\
\text { ratio }\end{array}$ & $\begin{array}{c}\text { Tensile strength } \\
(\mathrm{MPa})\end{array}$ & $\begin{array}{c}\text { Cohesive force } c \\
(\mathrm{MPa})\end{array}$ & $\begin{array}{c}\text { Internal friction } \\
\text { angle }\left(\varphi,{ }^{\circ}\right)\end{array}$ & $\begin{array}{c}\text { Flexural } \\
\text { strength (MPa) }\end{array}$ \\
\hline $\begin{array}{l}\text { Metamorphic fine } \\
\text { sandstone }\end{array}$ & 123.9 & 40.9 & 0.25 & 11.5 & 16.4 & 60.8 & 80.7 \\
\hline Andalusite schist & 102.6 & 26.9 & 0.17 & 11.9 & 9.8 & 57.4 & 94.4 \\
\hline Slate & 203.2 & 33.2 & 0.23 & 10.3 & 50.9 & 41.1 & 58.0 \\
\hline Limestone & 124.1 & 50.2 & 0.18 & 10.9 & 15.1 & 57.5 & 36.1 \\
\hline Granite & 158.9 & 29.0 & 0.26 & 8.0 & 28.0 & 58.9 & - \\
\hline Quartz sandstone & 147.3 & 29.9 & 0.22 & 11.3 & - & - & - \\
\hline Mica schist (vertical) & 152.4 & 74.0 & 0.11 & - & 26.3 & 56.9 & \multirow[b]{2}{*}{57.1} \\
\hline $\begin{array}{l}\text { Mica schist } \\
\text { (horizontal) }\end{array}$ & 183.0 & 34.5 & 0.18 & 14.5 & 8.2 & 71.4 & \\
\hline
\end{tabular}

TABLE 2: Rock mechanical parameters during FLAC3D simulation [19].

\begin{tabular}{|c|c|c|c|c|c|c|}
\hline Lithology & $\begin{array}{c}\text { Material } \\
\text { code }\end{array}$ & $\begin{array}{c}\text { Density } \\
\left(\mathrm{kg} \cdot \mathrm{m}^{-3}\right)\end{array}$ & $\begin{array}{c}\text { Bulk modulus } \\
(\mathrm{GPa})\end{array}$ & $\begin{array}{l}\text { Shear modulus } \\
(\mathrm{GPa})\end{array}$ & $\begin{array}{c}\text { Cohesion } \\
(\mathrm{MPa})\end{array}$ & $\begin{array}{c}\text { Friction angle } \\
\left({ }^{\circ}\right)\end{array}$ \\
\hline Quaternary & $\mathrm{Q}$ & 2000 & 1.02 & 0.87 & 15 & 20 \\
\hline Weathering layer & $\mathrm{FH}$ & 2560 & 1.15 & 0.9 .5 & 59 & 22 \\
\hline Limestone & h3 & 2830 & 5.15 & 5.15 & 210 & 41 \\
\hline Weathered fractured zone & $\mathrm{F}$ & 2260 & 0.915 & 8.95 & 15 & 27 \\
\hline Granite & $\mathrm{r}$ & 2600 & 6.25 & 4.30 & 247 & 44 \\
\hline Andalusite schist-1 & B4 & 2840 & 3.21 & 2.63 & 78.1 & 31 \\
\hline Quartz sandstone & B3-3 & 2282 & 3.01 & 2.17 & 74.5 & 30 \\
\hline Andalusite schist-2 & B3-2 & 2840 & 2.71 & 1.36 & 67.6 & 31 \\
\hline $\begin{array}{l}\text { Metamorphic fine } \\
\text { sandstone-1 }\end{array}$ & B3-1 & 2750 & 4.13 & 3.36 & 63.2 & 33 \\
\hline Mica schist & B2-2 & 2845 & 2.77 & 1.64 & 63 & 29.8 \\
\hline Andalusite schist- 3 & B2-1 & 2842 & 3.44 & 2.78 & 74 & 34 \\
\hline $\begin{array}{l}\text { Metamorphic fine } \\
\text { sandstone-2 }\end{array}$ & B1 & 2748 & 4.50 & 3.79 & 63 & 35 \\
\hline
\end{tabular}

\subsection{Stability Analysis of Numerical Open-Pit Model}

3.2.1. Stability Analysis of Open Pit in Current Situation. The stability analysis of the slope stability of southwest pit in current situation was conducted, and the numerical results are shown in Figure 3. In Figure 3, most damaged areas had local geological conditions that were more complex and the slope morphology was more unfavorable. The typical damaged locations were located at the north side of the east U-shaped groove, while the protruding position was at the middle part of the northern side. The two parts demonstrated a trend to expand westwards along the fracture zone to the lower part and upwards along the slope, while the other damage areas were relatively small. Both parts 


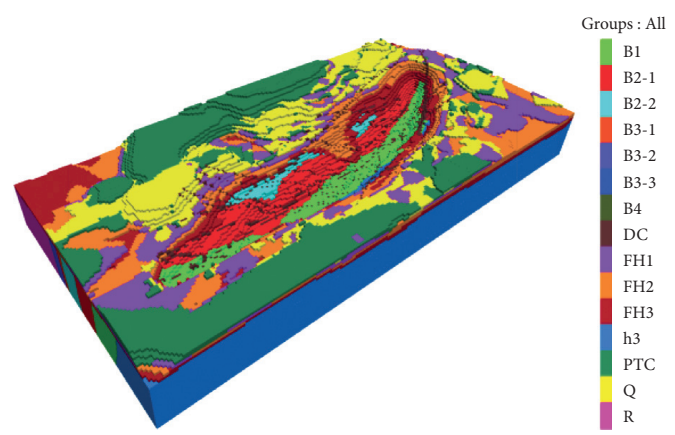

(a)

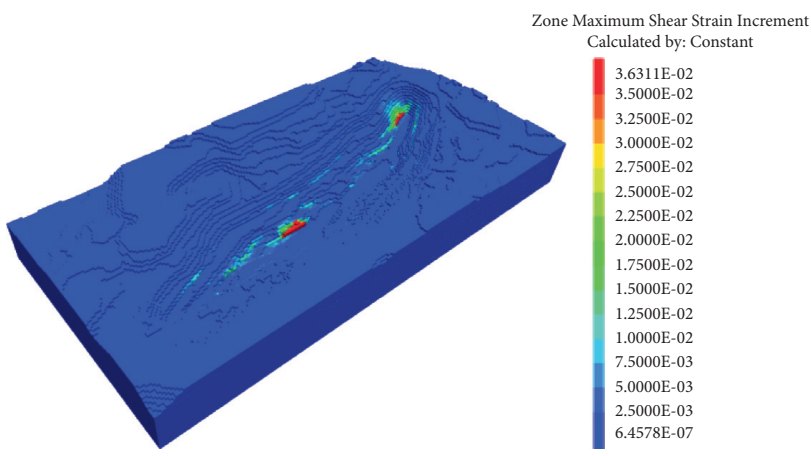

(c)

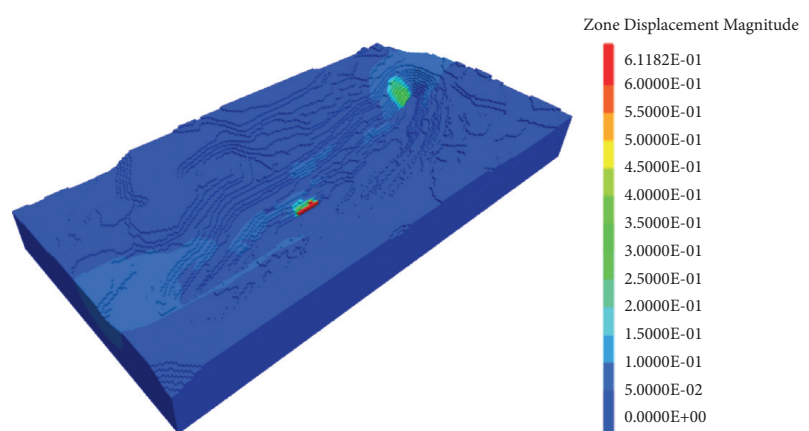

(b)

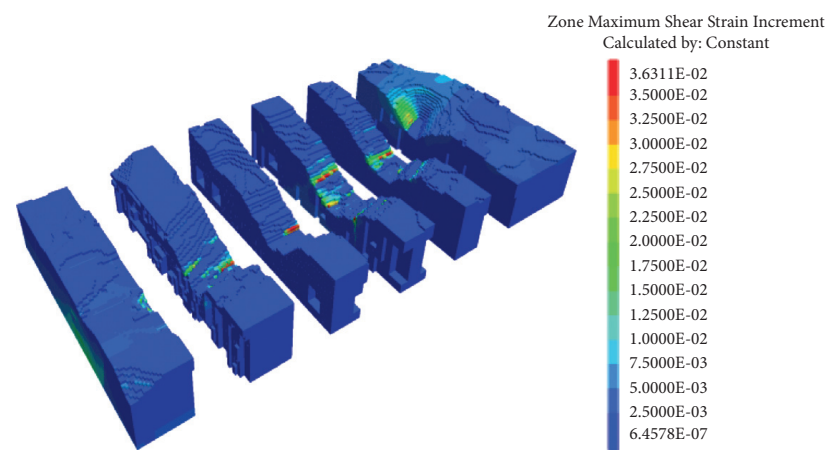

(d)

Figure 3: Numerical results of three-dimensional mine model in current situation. (a) Three-dimensional model of mining area. (b) Displacement after plastic deformation calculation. (c) Shear strain increment. (d) Slices of shear strain.

presented shallow point-shaped and line-shaped damage, while the southern side also sustained local damage, but relatively to the northern side, the numbers and scales were smaller.

\subsubsection{Stability Analysis of Slope Section in Current and Final} Boundary Situations. Considering the distribution of rock strata and landsides area, the north and south sides of southwest pit were divided into 13 calculation sections along the main pit axis, and the slope stability of southwest pit was evaluated (Figure 4).

Stability calculation of mining area was divided into two parts. The stability of current slope sections was firstly calculated. According to the designed final boundary of mine, the stabilities of slope sections in final boundary were calculated through numerical simulations. Due to the space limitations, calculation results of certain slope sections in current and final boundary situations are presented in Figures 5-7.

(1) W3 Slope Section Calculation Results. The W3 slope section in current situation was basically in a stable state, while local displacements occurred at the middle part of both sides. After excavation to the final boundary, local landslides occurred at the lower one-third position near pit bottom of northern side. The landslides were characterized by shallow sliding surfaces, small scopes, and severe instability near the slope surfaces (Figure 5).
(2) W8 Slope Section Calculation Results. The W8 slope section was stable and in equilibrium. After excavation, instability failure occurs at the foot of northern side and potential large-scale landslide might occur, due to the slope foot instability (Figure 6).

(3) W13 Slope Section Calculation Results. The W13 slope section in current situation was relatively stable, and small displacement might occur at the top of northern side. After excavation to the final boundary, large-displacement areas were mainly concentrated near a platform at the middle and lower part of the northern side, which might induce shallow landslides (Figure 7).

3.2.3. Analysis Results of Slope Stability. Through the numerical results of 13 slope sections, combined with the analysis results of overall open-pit stability, the potential slope vulnerable areas after the excavation of final boundary were comprehensively identified. The results demonstrated that W1-W3 slope sections in current situation were basically stable at the west U-shaped groove, while certain shallow damage might locally occur after the excavation of final boundary; W4-W7 slope sections on the west side of midline might present slip damages of various degrees after the excavation of final boundary; also, W8 slope section was easy to induce large-scale instability failure when the slope would be excavated to the joint zone at the slope foot; the other slope sections in the current and final boundary 


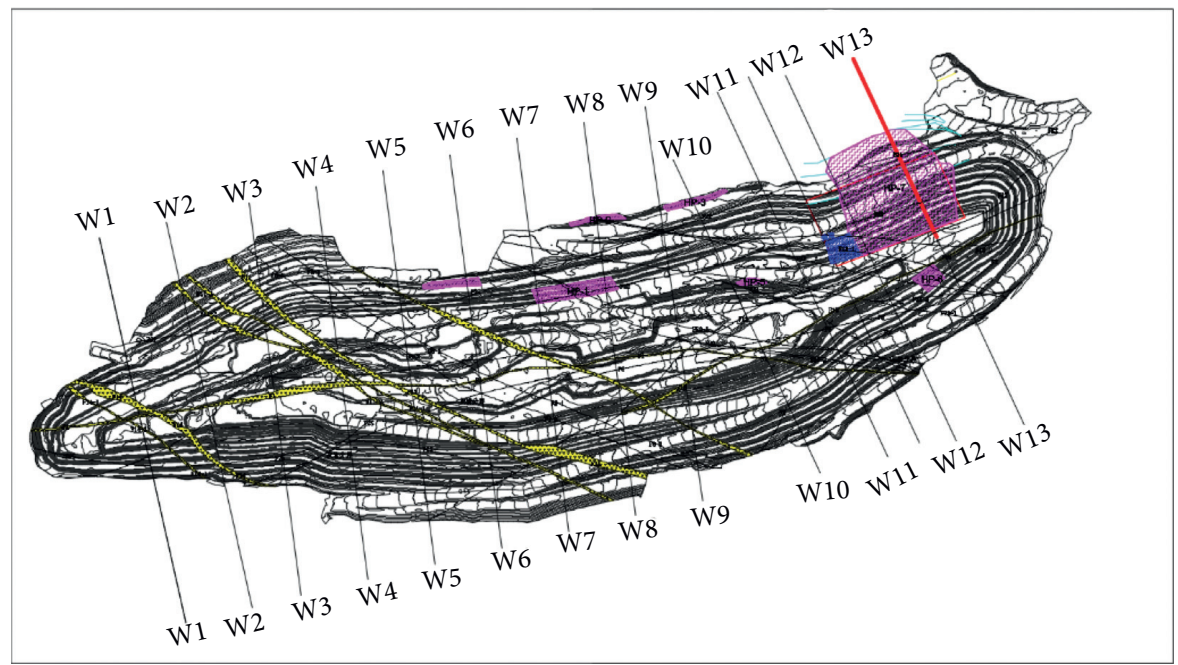

留脰 Landslide area

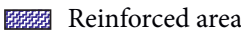

— Simulated section

Figure 4: Position of selected calculation slope section in open-pit mine [20].

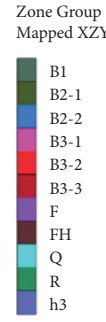

Zone Displacement

Mapped XZY

$6.1065 \mathrm{E}-02$

6.0000E- 02

$5.5000 \mathrm{E}-02$

$4.5000 \mathrm{E}-02$
$4.0000 \mathrm{E}-02$

$3.5000 \mathrm{E}-02$

$3.0000 \mathrm{E}-02$

$2.5000 \mathrm{E}-02$

$1.5000 \mathrm{E}-02$

$1.0000 \mathrm{E}-02$

$5.0000 \mathrm{E}-0$

$0.0000 \mathrm{E}+00$

Zone Displacement Mapped XZY

$2.9876 \mathrm{E}+00$
$2.7500 \mathrm{E}+00$
$2.5000 \mathrm{E}+00$

$2.5000 \mathrm{E}+00$
$2.2500 \mathrm{E}+00$

$2.0000 \mathrm{E}+00$
$1.7500 \mathrm{E}+00$

$1.5000 \mathrm{E}+00$

$1.2500 \mathrm{E}+00$

$7.5000 \mathrm{E}-01$

$5.0000 \mathrm{E}-01$

$5.0000 \mathrm{E}-01$
$2.5000 \mathrm{E}-01$

$0.0000 \mathrm{E}+00$

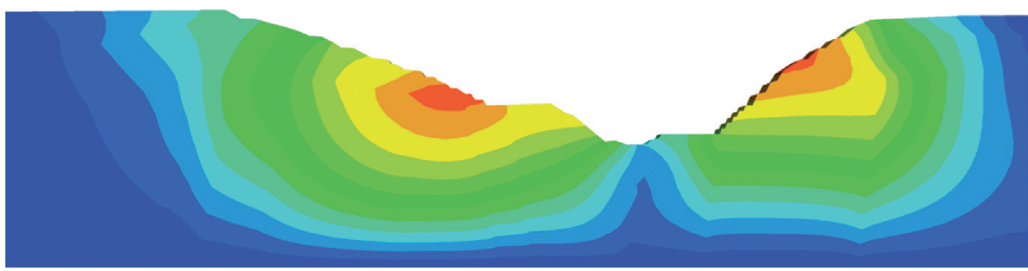

(b)

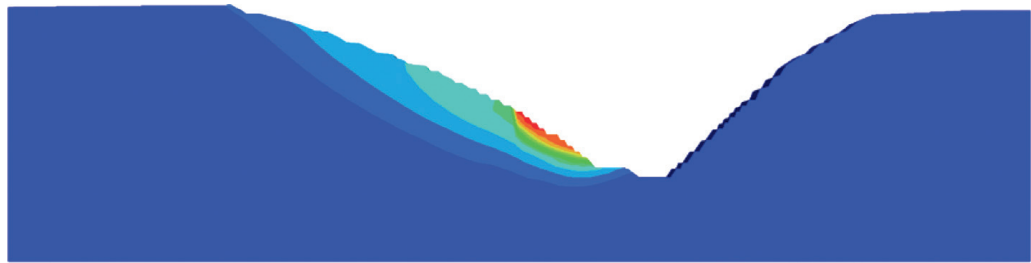

(c)

FIGURE 5: Calculated results of W3 slope section. (a) Section model of W3 slope. (b) Displacement of W3 slope section in current situation. (c) Displacement of W3 slope section in final boundary situation. 


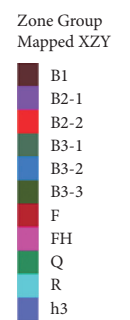

Zone Displacemen Mapped XZY
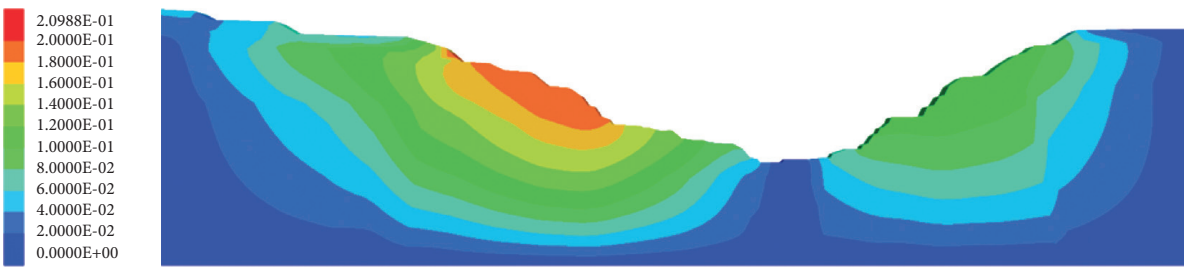

(b)
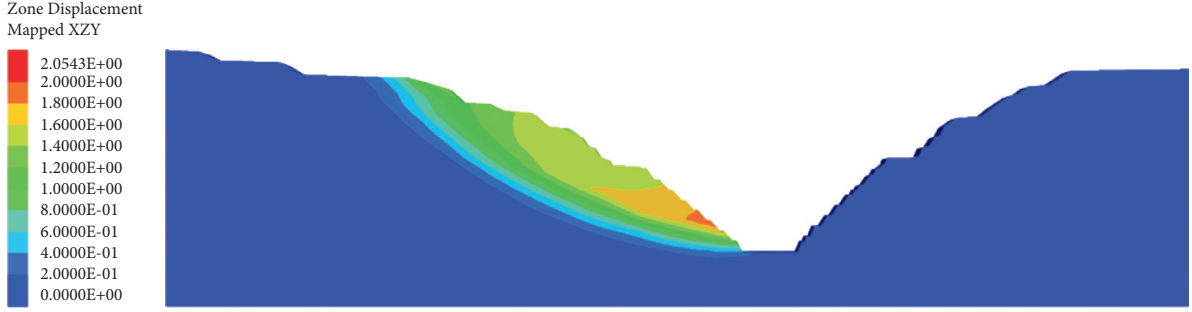

(c)

FIGURE 6: Calculated results of W8 slope section. (a) Section model of W8 slope. (b) Displacement of W8 slope section in current situation. (c) Displacement of W8 slope section in final boundary situation.

situations were relatively stable, while certain local instability failures might occur at W12 and W13 slope sections.

\section{Control Measure of NPR Cable in the Changshanhao Mine}

4.1. Limitations of Current Control Measures. With the increase of mining depth, various geological conditions become more complex. Although the slope had an anti-dip structure, a high portion of its rock mass was soft rock, while hard rock only existed in the form of interlayer and thin layer, which could not control the slope stability. As mining continued, the free surface of a rock mass and the gravitational potential energy also increased, while the joints were fully developed, in addition to rainfall, freeze-thaw, and blasting vibration, causing large-scale toppling failures in this open-pit mine. At present, the control measures used for slope reinforcement belong to small deformation materials or rigid materials, which cannot resist the special toppling collapse and large deformation of Changshanhao mine, resulting in sudden deformation and failure of slope. In addition, the rocks had creep and deterioration characteristics, as the slope was deforming. While the force exerted by landslide body on cable increased, when the cable force exceeded the tensile strength of cable itself, the cables sustained breakage. Subsequently, collapses and landslides occurred.
4.2. Control and Reinforcement Principle of NPR Cable. The cable is the main bearing body for slope protection and monitoring in open-pit mines worldwide. Currently, many energy-absorbing bolts, developed according to actual needs, could resist high deformation and failure of rock mass within a certain range, despite different energy-absorption characteristics through stretching, compression, and necking of a component, while these bolts do not have negative Poisson ratio performance, not really overcoming the necking breakage and support failure of cable. Considering the mechanical properties limitation of traditional cables, He (2010) developed a negative Poisson's ratio (NPR) cable with the properties of high constant resistance force and large elongation to control the large deformation of slope. Since the development of NPR cable, NPR cables have been successfully applied to the field stability monitoring and control of many open-pit slopes, producing significant results. NPR cable consists of a cable shank, connector, and constant resistance device (constant resistance body and sleeve), along with tray and nut. Figure 8 presents the structure of an NPR cable [21]. Constant resistance body is a standard cone, the constant resistance sleeve is a standard cylinder with uniform wall thickness, and the cable shank is a uniform diameter-equivalent pole. Constant resistance body and the sleeve together form a constant resistance device to provide a constant support resistance to the cable. The diameter of constant resistance body exceeds the 


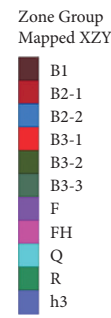

Zone Displacement Zone Displace
Mapped XZY

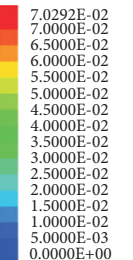

$0.0000 \mathrm{E}+00$

Zone Displacemen Mapped XZY
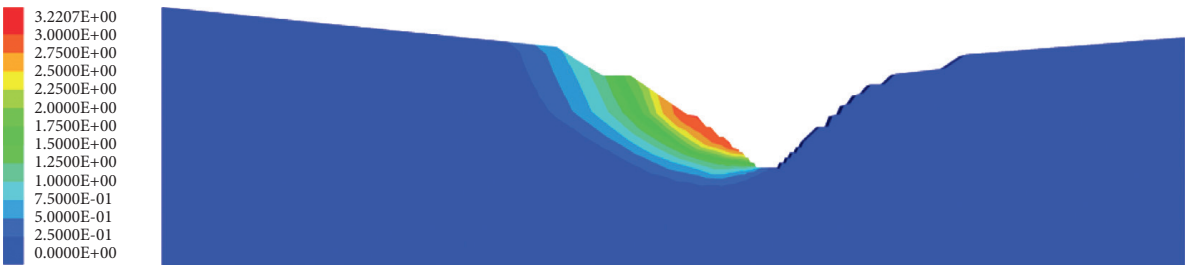

(c)

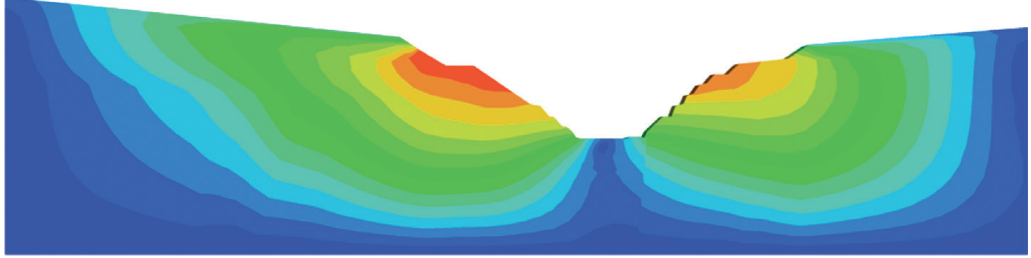

(b)

(a)

c)

Figure 7: Calculated results of W13 slope section. (a) Section model of W13 slope. (b) Displacement of W13 slope section in current situation. (c) Displacement of W13 slope section in final boundary situation.

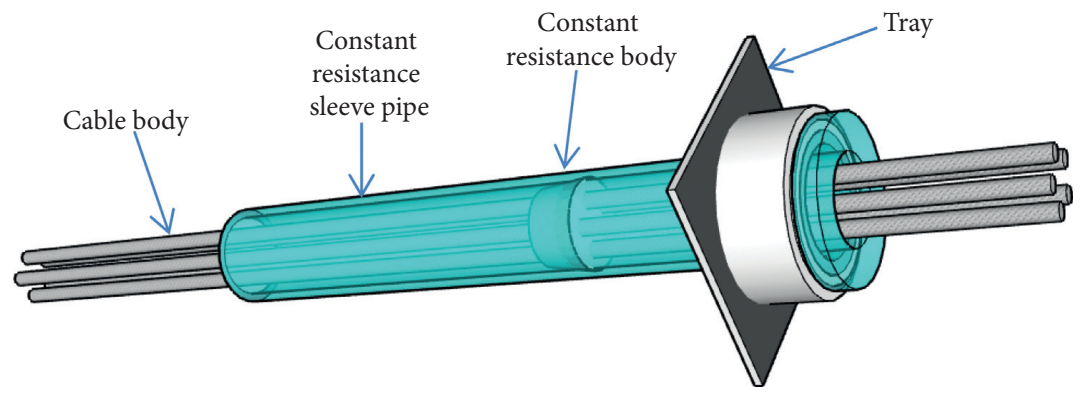

Figure 8: Structure diagram of NPR cable.

diameter of cable shank and is slightly larger than the inner diameter of the constant resistance sleeve. The working resistance of the cable might be produced between the sleeve and the cone, when an external load acts on the cable shank.

4.3. Analysis of Reinforcement Effect of NPR Cable. Based on the energy-absorption reinforcement mechanics through NPR cables, the control effects of ordinary (PR cable) and NPR cables on the toppling failure in the mining area were studied through the numerical calculation method. In this calculation, the typical destroyed W13 slope section was taken as the as the numerical simulation example (Figure 4). This section was located at the destroyed landslide area of the east U-shaped area. In the earlier period, the reinforcement design and construction of PR cable were carried out in this area. However, due to the limitation of small deformation of supporting materials, the original supporting area presented cable breakage, anchor head damage, local collapse, and deformation failure. Therefore, it was necessary and appropriate to select this section to simulate and compare the control effects of NPR and PR cables on the toppling failure in the open-pit mine.

The geophysical data demonstrated that the bending fracture surface depth was approximately $20 \mathrm{~m}$. Due to finite difference principle limitations, the block element of FLAC3D software could not simulate the slope toppling failure form. Consequently, the interface element was used 


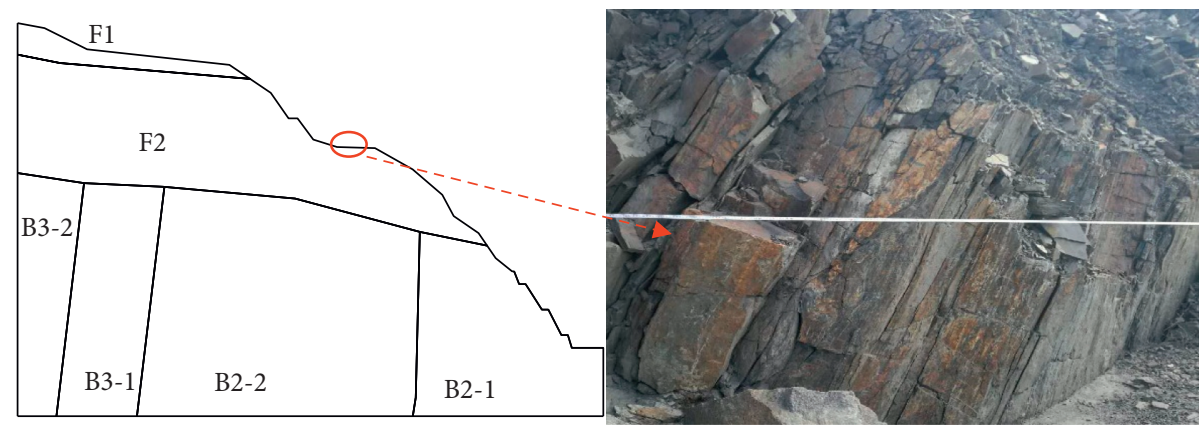

(a)

(b)

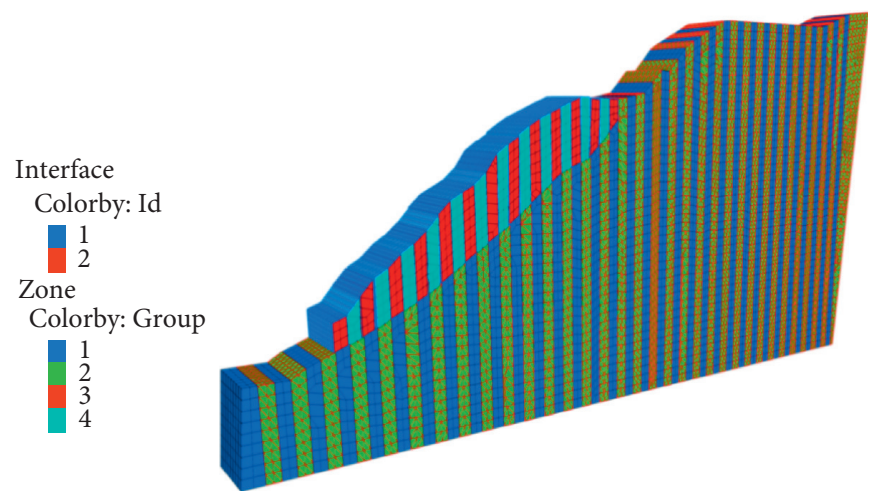

(c)

Figure 9: Calculation mode establishment of W13 slope section. (a) Morphology of W13 section. (b) Slope toppling failure. (c) Calculation model of W13 section.

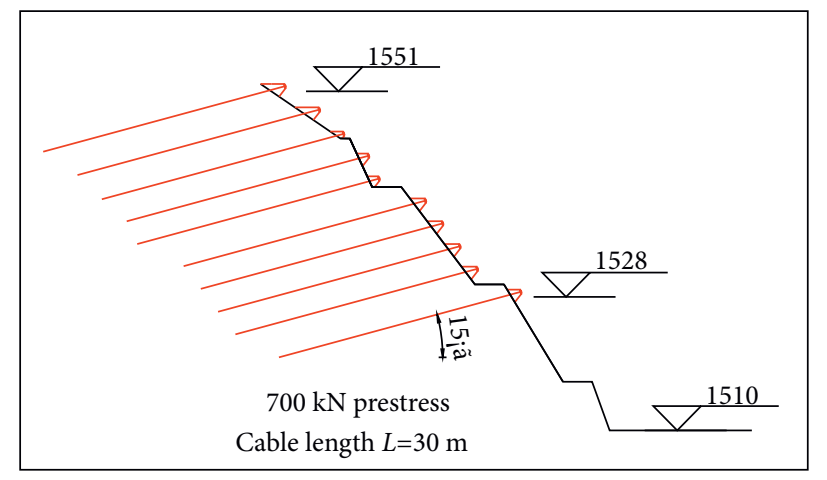

(a)

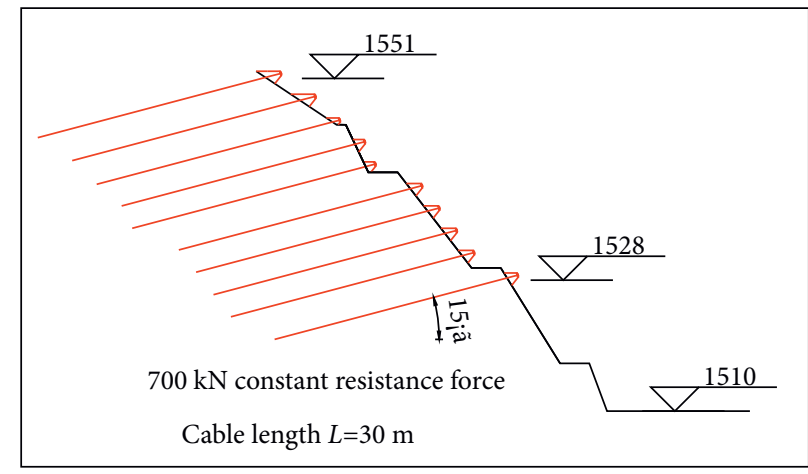

(b)
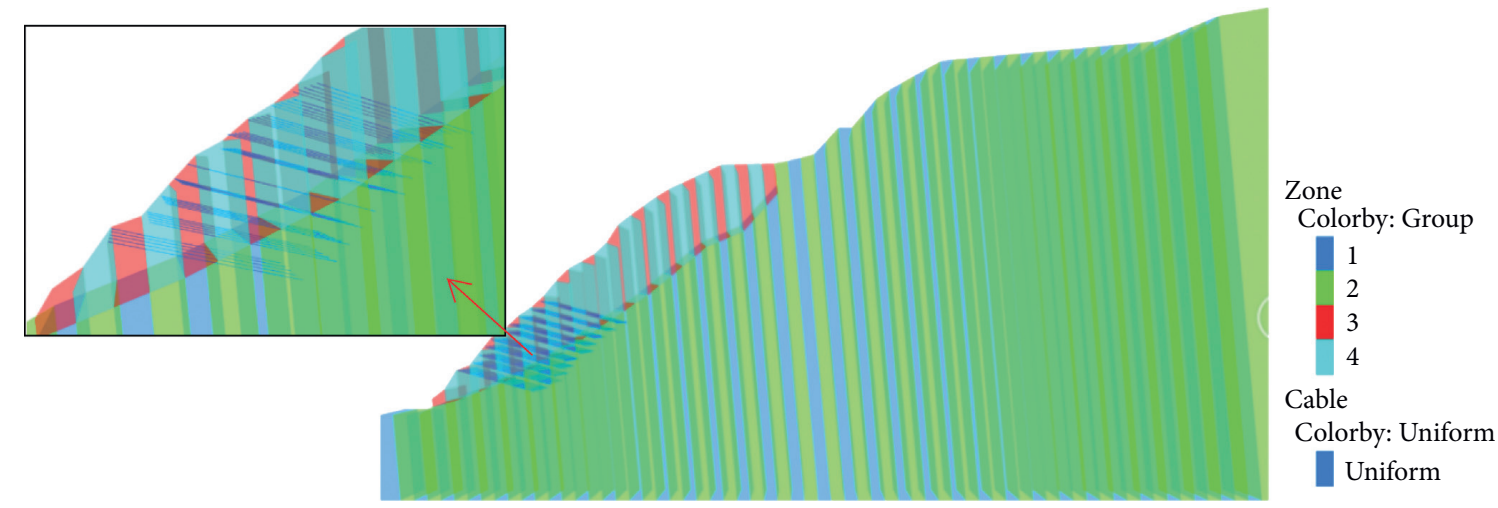

(c)

FIgURE 10: Reinforcement model of W13 slope section. (a) Reinforcement section of ordinary cable. (b) Reinforcement section of NPR cable. (c) FLAC3D model of slope reinforced by cables. 
TABLE 3: Strength parameters of rock block.

\begin{tabular}{lccccc}
\hline Strength parameter & Density $\left(\mathrm{kg} \cdot \mathrm{m}^{-3}\right)$ & Bulk modulus $(\mathrm{GPa})$ & Shear modulus $(\mathrm{GPa})$ & Cohesion $(\mathrm{MPa})$ & Friction angle $\left(^{\circ}\right)$ \\
\hline Rock block & 2300 & 53 & 21 & 1.5 & 45 \\
\hline
\end{tabular}

TABLE 4: Strength parameters of interface.

\begin{tabular}{lcccc}
\hline Strength parameter & Normal stiffness $(\mathrm{GPa})$ & Tangential stiffness $(\mathrm{GPa})$ & Cohesion $(\mathrm{kPa})$ & Friction angle $\left({ }^{\circ}\right)$ \\
\hline Interface & 53 & 21 & 10 & 20 \\
\hline
\end{tabular}

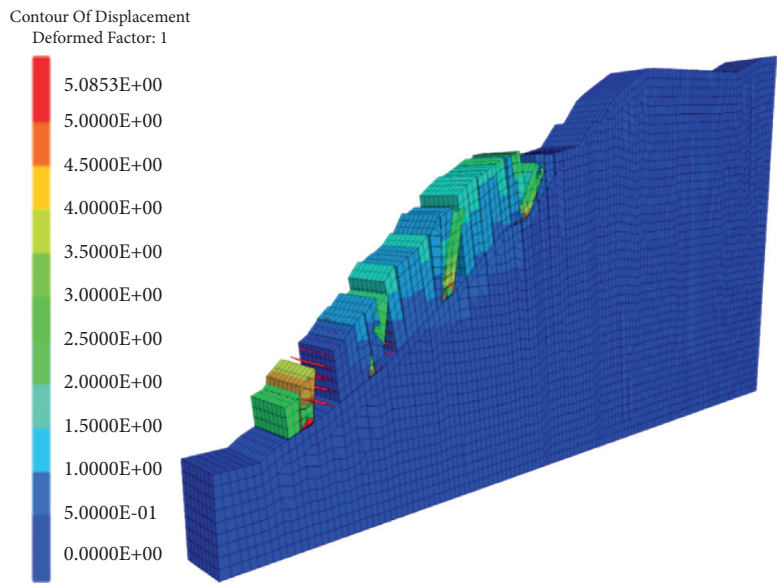

(a)

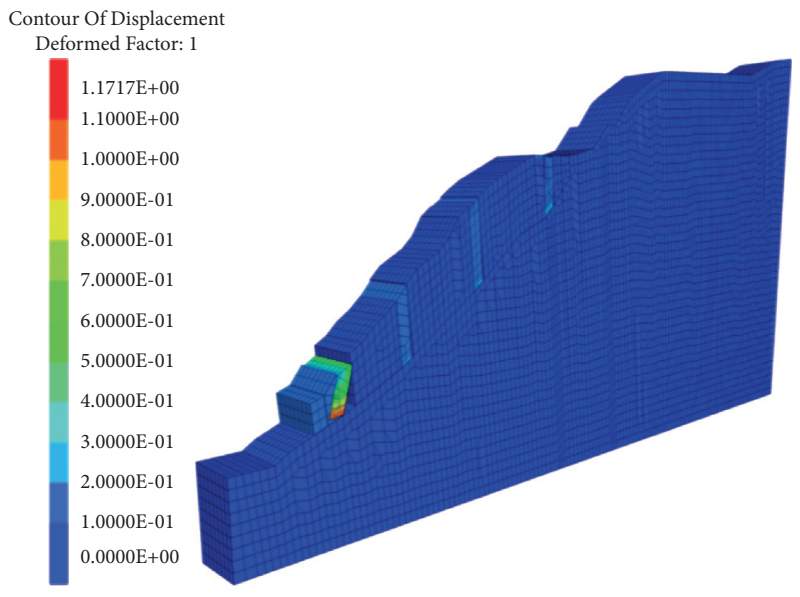

(b)

FIGURE 11: Rock mass displacement comparison after PR and NPR cable reinforcement of slope. (a) Displacement of slope reinforced with PR cable. (b) Displacement of slope reinforced with NPR cable.

to wrap the pseudo-destructive body, for the interaction between the destroying bodies to be realized through the interface. The lithology of the slope section could not be assigned according to the actual situation, due to the simplification of joints during modeling. In addition, the rock block strength in this area was relatively high, while the research results demonstrated that the sliding failure was mainly controlled by the joints. Therefore, the lithology could be assigned to a higher strength, while the structural plane could be assigned according to the actual strength. The corresponding numerical model is presented in Figure 9.

The slope of the study area was established, and consequently the NPR and ordinary cable units were, respectively, inserted. The support effect was analyzed through the cable force and slope displacement recording. Considering the supporting parameters of cables designed in the previous reinforcement scheme, 10 rows of cables were designed along the slope in this simulation. Five cables existed in each row with a distance of $4 \mathrm{~m}$ along the thickness direction. Among these, the length of the cable was $30 \mathrm{~m}$ and the length of anchorage section was $10 \mathrm{~m}$, while the angle between the axis of cable and the horizontal plane was 15 degrees, but the designed prestress of ordinary cables was $70 \mathrm{kN}$. Also, the constant resistance force of NPR cables was $70 \mathrm{kN}$. The reinforcement parameters are presented in Figure 10.

After the establishment of slope model, the parameters of relevant rock mass and interface were assigned and the stability calculation was carried out. Since the collapse failures could not converge during calculation, the final calculation steps were set to 30000 . The calculation parameters are presented in Tables 3 and 4, while the calculation results are presented in Figure 11.

Through the displacement comparison of the slope strengthened by two different cables, it could be observed that the toppling failure of slope had not been significantly improved after the ordinary cable reinforcement of $70 \mathrm{kN}$ prestress, while the entire sliding body demonstrated largescale deformation failure. Due to the limitation of the software, the sliding body element could not be subdivided into smaller sliders. Consequently, irregular toppling occurred. On the other hand, after the reinforcement with NPR cables of $70 \mathrm{kN}$ in constant resistance force, the slope failure was effectively restrained, while only local failure occurred at the lower slope foot. In addition, the effective energy of slope was released after the small displacement of upper part of the sliding body, so that the overall slope maintained a better stability (Figure 12).

Through the axial force comparison of two cables after failure, it could be observed that the ordinary cable sustained breakage and pull-out failure, the cable axial force had returned to zero, and the anchorage section still remained within the rock mass, while the upper anchorage section was suspended and in failure state. This was similar to the field failure phenomena. Besides the local failure of the lower part, all NPR cables were maintained at an excellent constant resistance force state. NPR cables in the middle and lower 


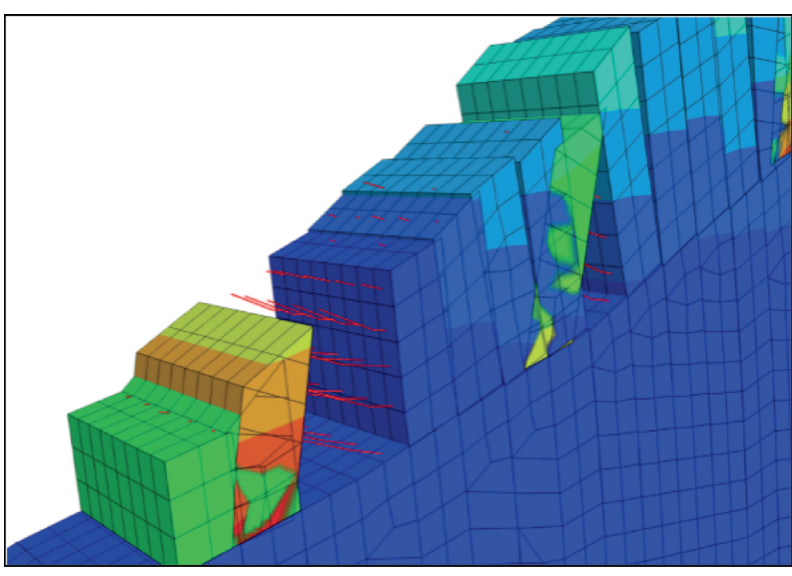

(a)

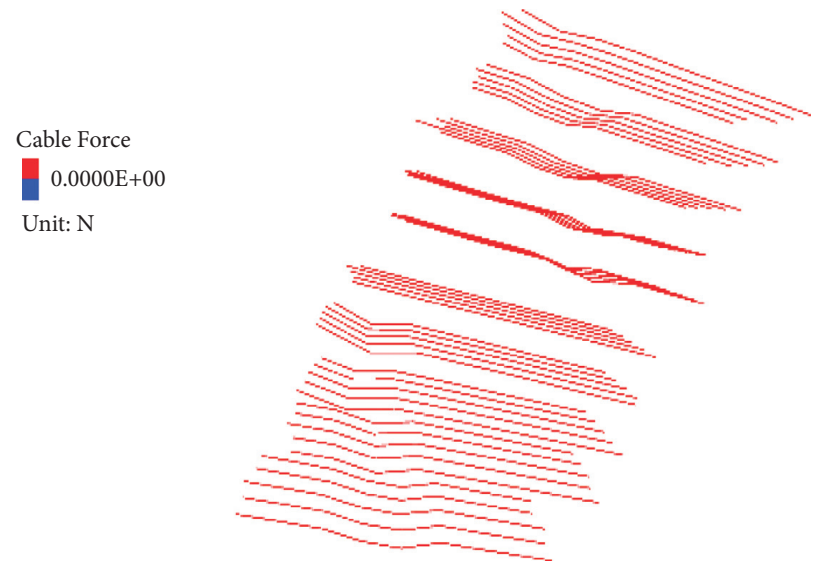

(c)

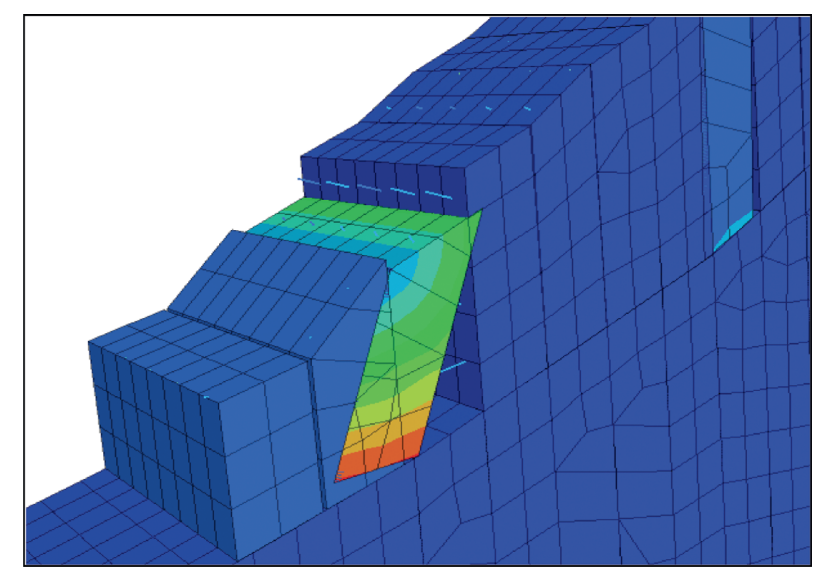

(b)

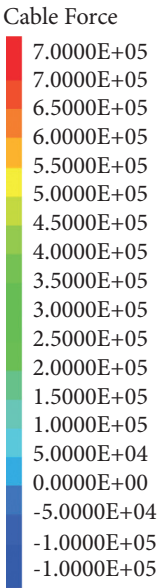

$-1.0000 \mathrm{E}+05$

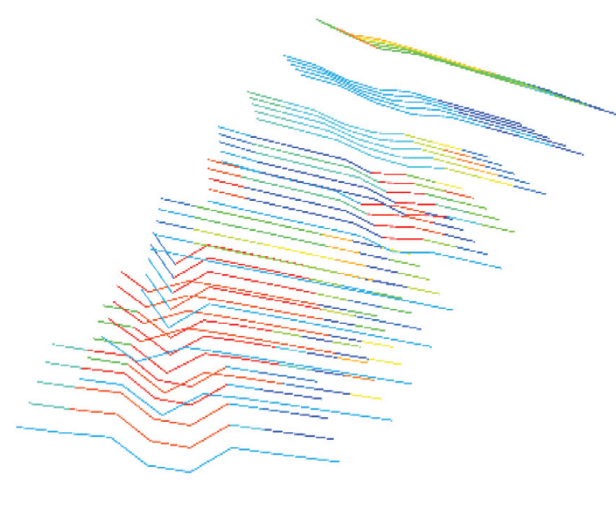

(d)

FIgURE 12: Slope characteristics after NPR and PR cable support. (a) Tensile behavior of PR cable under deformation. (b) Tensile behavior of NPR cable under deformation. (c) Axis force distribution nephogram of PR cable. (d) Axis force distribution nephogram of NPR cable.

part reached the designed constant resistance force of $70 \mathrm{kN}$. In general, this simulation reflected the superior reinforcement performance (stable constant resistance force and large deformation) of NPR cable for the toppling failure. Moreover, its characteristics of energy absorption and unloading could effectively control the overall landslide induced by local instability. Therefore, it was recommended that NPR cables should be used to reinforce the surrounding area of W4-W8 slope sections, which might sustain potential large-scale landslides after the final boundary excavation, ensuring the safe and effective mining of the open-pit mine.

\section{Conclusions}

According to the field geological investigation and numerical results, the control mechanism of NPR cable on the toppling failure of anti-dip slope was studied, the corresponding reinforcement methods in the failure areas were proposed, and certain conclusions were drawn as follows:

(1) Based on the field engineering geological survey, the current slope characteristics were obtained, and combined with the field drilling data, the three-dimensional engineering geological model of Changshanhao mine was built. It was found that typical damage locations were located at the north side of east U-shaped groove, while the protruding position was at the middle part of the northern side.

(2) Through the slope stability of entire open-pit slope and selection of 13 slope sections in current and designed final boundary situations, these were estimated through FLAC3D software, and the potential vulnerable areas of slope after the excavation to final boundary were comprehensively identified.

(3) NPR cable could maintain constant resistance force and large deformation during the slope deformation. Based on the reinforcement mechanics of NPR cable, the typical destroyed W13 slope section was taken as the testing area, for which the controlling effects of ordinary (PR cable) and NPR cables on the toppling failure in the mining area were studied through numerical calculation. The controlling effects of NPR cable on the toppling failure of anti-dip slope were proved. 


\section{Data Availability}

The data, models, and codes that support the findings of this study are available from the corresponding author upon reasonable request.

\section{Conflicts of Interest}

The authors declare that they have no conflicts of interest.

\section{Acknowledgments}

This study was supported by the Henan Key Laboratory of Geological Environment Intelligent Monitoring and Disaster Prevention (ZDZX2020002), State Key Laboratory for Geomechanics and Deep Underground Engineering, China University of Mining and Technology, Beijing (SKLGDUEK2133), Guizhou Province Science and Technology Plan Project ([2019]2843), Technology Top Talent Support Project of Guizhou Provincial Education Department ([2020]155), and Research and Development Project of Guizhou University of Engineering Science (G2018016).

\section{References}

[1] F. C. Dai, C. F. Lee, and Y. Y. Ngai, "Landslide risk assessment and management: an overview," Engineering Geology, vol. 64, no. 1, pp. 65-87, 2002.

[2] J. Zhou, E. Li, S. Yang et al., "Slope stability prediction for circular mode failure using gradient boosting machine approach based on an updated database of case histories," Safety Science, vol. 118, pp. 505-518, 2019.

[3] T. K. Nian, G. Q. Chen, M. T. Luan, Q. Yang, and D. F. Zheng, "Limit analysis of the stability of slopes reinforced with piles against landslide in nonhomogeneous and anisotropic soils," Canadian Geotechnical Journal, vol. 45, no. 8, pp. 1092-1103, 2008.

[4] S. K. Das, R. K. Biswal, N. Sivakugan, and B. Das, "Classification of slopes and prediction of factor of safety using differential evolution neural networks," Environmental Earth Sciences, vol. 64, no. 1, pp. 201-210, 2011.

[5] W. Gao, "Stability analysis of rock slope based on an abstraction ant colony clustering algorithm," Environmental Earth Sciences, vol. 73, no. 12, pp. 7969-7982, 2015.

[6] M. L. Napoli, M. Barbero, E. Ravera, and C. Scavia, "A stochastic approach to slope stability analysis in bimrocks," International Journal of Rock Mechanics and Mining Sciences, vol. 101, pp. 41-49, 2018.

[7] M. Morales, K. K. Panthi, and K. Botsialas, "Slope stability assessment of an open pit mine using three-dimensional rock mass modeling," Bulletin of Engineering Geology and the Environment, vol. 78, no. 2, pp. 1249-1264, 2019.

[8] J. Zhang, P. He, J. Xiao, and F. Xu, "Risk assessment model of expansive soil slope stability based on Fuzzy-AHP method and its engineering application," Geomatics, Natural Hazards and Risk, vol. 9, no. 1, pp. 389-402, 2018.

[9] Y. He, Y. Liu, H. Hazarika, and R. Yuan, "Stability analysis of seismic slopes with tensile strength cut-off," Computers and Geotechnics, vol. 112, pp. 245-256, 2019.

[10] J.-H. Wu, W.-K. Lin, and H.-T. Hu, "Post-failure simulations of a large slope failure using 3DEC: the Hsien-du-Shan slope," Engineering Geology, vol. 242, pp. 92-107, 2018.
[11] E. Ausilio, E. Conte, and G. Dente, "Seismic stability analysis of reinforced slopes," Soil Dynamics and Earthquake Engineering, vol. 19, no. 2, pp. 591-611, 2000.

[12] E. A. Ellis, I. K. Durrani, and D. J. Reddish, "Numerical modelling of discrete pile rows for slope stability and generic guidance for design," Géotechnique, vol. 60, no. 3, pp. 185-195, 2010.

[13] X. Li, X. Pei, M. Gutierrez, and S. He, "Optimal location of piles in slope stabilization by limit analysis," Acta Geotechnica, vol. 7, no. 3, pp. 253-259, 2012.

[14] H. Su, J. Hu, and M. Yang, "Evaluation method for slope stability under multianchor support," Natural Hazards Review, vol. 16, no. 4, Article ID 04014034, 2015.

[15] P. Zou, X. Zhao, Z. Meng, A. Li, Z. Liu, and W. Hu, "A slope stability analysis for southern Wuchangping tin mine," Journal of Vibroengineering, vol. 21, no. 4, pp. 998-1014, 2019.

[16] Y. Wang, Z. Shu, Y. Zheng, and S. Xiao, "Plant root reinforcement effect for coastal slope stability," Journal of Coastal Research, vol. 73, pp. 216-219, 2015.

[17] S. Ye, G. Fang, and Y. Zhu, "Model establishment and response analysis of slope reinforced by frame with prestressed anchors under seismic considering the prestress," Soil Dynamics and Earthquake Engineering, vol. 122, pp. 228-234, 2019.

[18] T.-K. Nian, J.-C. Jiang, and F.-W. Wang, "Seismic stability analysis of slope reinforced with a row of piles," Soil Dynamics and Earthquake Engineering, vol. 84, pp. 83-93, 2016.

[19] Z. G. Tao, C. Zhu, M. C. He, and K. M. Liu, "Research on the safe mining depth of anti-dip bedding slope in Changshanhao Mine," Geomechanics and Geophysics for Geo-Energy and GeoResources, vol. 36, no. 6, pp. 1-20, 2020.

[20] Z. G. Tao, S. L. Ren, S. H. Pang, H. T. Xu, and M. C. He, "Study on $3 \mathrm{D}$ modeling method and reinforcement scheme of large and complex open-pit mine," Journal of Mining Science and Technology, vol. 6, no. 4, pp. 397-408, 2021.

[21] Z. Tao, Y. Wang, C. Zhu, H. Xu, G. Li, and M. He, "Mechanical evolution of constant resistance and large deformation anchor cables and their application in landslide monitoring," Bulletin of Engineering Geology and the Environment, vol. 78, no. 7, pp. 4787-4803, 2019. 